\title{
Effectiveness of different silicone oil remove methods after vitrectomy and light silicone oil tamponade in elderly patients
}

\author{
Xiaobo Wan ${ }^{1}$, Jingbo $\mathrm{Li}^{2}$, Qiguang $\mathrm{Liu}^{2}$ \\ ${ }^{1}$ Department of Ophthalmology, Liuzhou People's Hospital, Liuzhou 545006, China; ${ }^{2}$ Department of Ophthalmology, Liuzhou Hospital of \\ Traditional Chinese Medicine, Liuzhou 545006, China \\ Contributions: (I) Conception and design: X Wan; (II) Administrative support: X Wan; (III) Provision of study materials or patients: X Wan; (IV) \\ Collection and assembly of data: J Li; (V) Data analysis and interpretation: Q Liu; (VI) Manuscript writing: All authors; (VII) Final approval of \\ manuscript: All authors. \\ Correspondence to: Xiaobo Wan. Department of Ophthalmology, Liuzhou People’s Hospital, Liuzhou 545006, China. Email: wanxiaobo_gx@163.com.
}

Background: During the remove of oil from the silicone oil-filled eye after vitrectomy, perfusion fluid is often mistakenly aspirated when mechanical force is used to remove the oil. This leads to a sudden sharp drop in intraocular pressure and collapse of the eyeball, which may cause complications. The aspiration of perfusion fluid can be detected when the oil is removed manually, and the force of the hand and location of the aspiration can be adjusted to remove the silicone oil instead. In this study, we assessed the efficacy and safety of a manual 23-gauge (23G) silicone oil remove method and confirmed that this is a feasible, highly efficient, safe, simple and economical way to remove oil.

Methods: We recruited 130 patients (130 affected eyes) 3-6 months after they had undergone vitrectomy and light silicone oil tamponade at our hospital. The patients/eyes were randomly divided into two groups (manual or vitrectomy system), with 65 eyes in each group. All eyes in both groups underwent $23 \mathrm{G}$ oil remove by the same physician. The following aspects of the two groups were compared: (I) oil remove duration; (II) average intraocular pressure at 1 day, 1 week and 1 month after the procedure; and (III) postoperative complications, such as retinal redetachment, silicone oil residue, massive suprachoroidal hemorrhage and choroid detachment.

Results: The average oil remove durations of the manual group and the vitrectomy system group were $5.92 \pm 1.34$ and $8.87 \pm 1.68$ min, respectively $(\mathrm{P}<0.05)$; the duration for the manual group was significantly shorter than that for the vitrectomy system group $(\mathrm{t}=11.07, \mathrm{P}=0)$. The average intraocular pressures at 1 day, 1 week and 1 month after operation of the manual group were $10.2 \pm 2.7,15.2 \pm 3.5$ and $17.2 \pm 3.1 \mathrm{mmHg}$, respectively, and those of the vitrectomy system group were 9.8 $\pm 2.4,15.5 \pm 3.1$ and $16.8 \pm 3.4 \mathrm{mmHg}$, respectively; the differences between the two groups were not statistically significant at any time point ( $\mathrm{t}=0.892, \mathrm{P}=0.374$ at 1 day; $\mathrm{t}=0.517, \mathrm{P}=0.606$ at 1 week; and $\mathrm{t}=0.701, \mathrm{P}=0.485$ at 1 month). The difference in the incidence of postoperative complications, including retinal redetachment, silicone oil residue, massive suprachoroidal hemorrhage and choroid detachment, between the two groups was statistically significant $\left(\chi^{2}=4.2787, \mathrm{P}=0.0386\right)$. None of the affected eyes were complicated with transient intraocular hypotension, vitreous hemorrhage or endophthalmitis.

Conclusions: The manual 23G silicone oil remove method is highly efficient, safe, simple and economical and can be used conveniently and clinically by the majority of medical institutions.

Keywords: Vitrectomy; silicone oil; 23-gauge (23G); microcannula

Submitted Mar 09, 2020. Accepted for publication Apr 30, 2020.

doi: $10.21037 /$ apm-20-949

View this article at: http://dx.doi.org/10.21037/apm-20-949 


\section{Introduction}

At present, vitrectomy combined with silicone oil tamponade has obvious advantages for closing retinal holes, resetting the retina and restoring vision for the treatment of complicated retinal detachment, severe eye trauma, suppurative endophthalmitis and intraocular tumors (1). Due to the biological actions of the eye tissue, the silicone oil used to fill the eye will often emulsify after a certain period of time and can cause various complications (2), such as complicated cataract, secondary glaucoma, corneal endothelial decompensation and band-shaped corneal degeneration. Cheng et al. (3) found that long-term silicone oil placement in the eye can cause degenerative changes of the retina, leading to dissolution and breakage of the retinal tissue structure. Most scholars believe that it is the best to remove silicone oil 3-6 months after the retina has stabilized (4).

There are many ways to remove silicone oil. Depending on the incision locations, oil can be removed from the corneal tunnel through the pupil or from the pars plana. The incision diameter may be 20 -gauge $(\mathrm{G}), 23 \mathrm{G}$ or $25 \mathrm{G}$. In terms of incision repair after surgery, remove may be sutured or sutureless. The suction method used can involve active aspiration or passive perfusion (5). Remove via the corneal tunnel through the pupil is often used in cases with incomplete lens capsule; however, it has limitations and can cause corneal endothelium damage. Currently, increasing numbers of medical institutions remove silicone oil through the sclera plana using a $20 \mathrm{G}$ incision since the method is efficient, simple and economical. However, this method also has disadvantages, such as the need to cut open the conjunctiva, the large incision required at the conjunctiva and sclera, the lack of microcannula protection at the incision, the repeated passage of the oil remove needle into and out of the vitreous cavity, and the creation of iatrogenic retinal holes and retinal redetachment caused by pulling the retina surrounding the incision. In recent years, with the extensive clinical application of $23 \mathrm{G}$ and $25 \mathrm{G}$ vitrectomy, many clinicians have used these systems for active silicone oil remove to avoid the shortcomings of remove via $20 \mathrm{G}$ sclera plana incision, which include large incisions, injury and a lack of microcannula protection. However, $23 \mathrm{G}$ and $25 \mathrm{G}$ vitrectomy methods also have disadvantages in clinical application, such as the high cost of $23 \mathrm{G}$ and $25 \mathrm{G}$ surgical kits, the low efficiency of oil remove and the likelihood of eye collapse due to the high negative pressure of the machine during oil remove (6). Therefore, we cut a section of the polyethylene infusion tube and connected it to a $5-\mathrm{mL}$ syringe. Approximately $3 \mathrm{~mm}$ of the polyethylene infusion tube was exposed. The tube was placed on the microcannula of the supratemporal $23 \mathrm{G}$ scleral puncture, perpendicular to the scleral surface. The silicone oil was removed by the negative pressure generated by pulling the piston handle by hand. Compared with methods of vitrectomy system, this method is simple and has excellent efficacy. We report this method below.

We present the following article in accordance with the STROBE reporting checklist (available at http://dx.doi. org/10.21037/apm-20-949).

\section{Methods}

\section{Subjects}

Patients who had undergone vitrectomy combined with light silicone oil tamponade 3-6 months were recruited from our hospital between Jan 2016 and Jan 2018. The study was approved by the ethics committee of the hospital, and all patients signed informed consent. The eyes were stable, the retinas were recovered, and the holes were closed. A total of 130 patients (130 eyes) were included in the study, including 73 males ( 73 eyes) and 57 females (57 eyes). The age ranged from 60 to 75 years, and the average age was $65.6 \pm 15.7$ years. Prior to the surgery, all patients underwent best corrected visual acuity testing (LogMAR BCVA), intraocular pressure testing, slit-lamp microscopy, indirect ophthalmoscopy and A and B-mode ultrasound evaluation. Patients with glaucoma, recurrent retinal detachment, choroidal hemorrhage and detachment prior to the operation were excluded. According to Random number table, patients were randomly divided into two groups, including 65 eyes in the manual oil remove group and 65 eyes in the vitrectomy system oil remove group. The $23 \mathrm{G}$ silicone oil removes of the patients in both groups were completed by the same physician.

The general conditions of the two groups of patients did not differ significantly $(\mathrm{P}>0.05)$ (Table 1$)$.

\section{Procedure}

Prior to surgery, the pupils of both groups were fully dilated, and the patients underwent retrobulbar anesthesia with $2.5 \mathrm{~mL} 0.75 \%$ ropivacaine. If combined cataract surgery was required, the patients first underwent phacoemulsification cataract surgery and intraocular lens implantation, followed 
Table 1 Comparison of the general conditions of the two groups of patients

\begin{tabular}{|c|c|c|c|c|c|c|}
\hline Group & $\begin{array}{l}\text { Number } \\
\text { of eyes }\end{array}$ & $\begin{array}{c}\text { Sex } \\
\text { (male/female) }\end{array}$ & $\begin{array}{l}\text { Average age } \\
\text { (years) }\end{array}$ & $\begin{array}{l}\text { Silicone oil tamponade } \\
\text { duration (months) }\end{array}$ & $\begin{array}{c}\text { Average preoperative } \\
\text { LogMAR BCVA }\end{array}$ & $\begin{array}{l}\text { Average postoperative } \\
\text { intraocular pressure }\end{array}$ \\
\hline $\begin{array}{l}\text { Manual oil remove } \\
\text { group }\end{array}$ & 65 & $35 / 30$ & $65.1 \pm 14.3$ & $4.3 \pm 1.2$ & $1.72 \pm 6.1$ & $17.8 \pm 4.0$ \\
\hline $\begin{array}{l}\text { Vitrectomy system oil } \\
\text { remove group }\end{array}$ & 65 & $38 / 27$ & $66.2 \pm 17.1$ & $4.6 \pm 1.4$ & $1.70 \pm 0.54$ & $17.3 \pm 4.5$ \\
\hline $\mathrm{t}$ value & - & - & 0.398 & 1.312 & 0.132 & 0.669 \\
\hline$P$ value & - & 0.60 & 0.69 & 0.192 & 0.896 & 0.504 \\
\hline
\end{tabular}

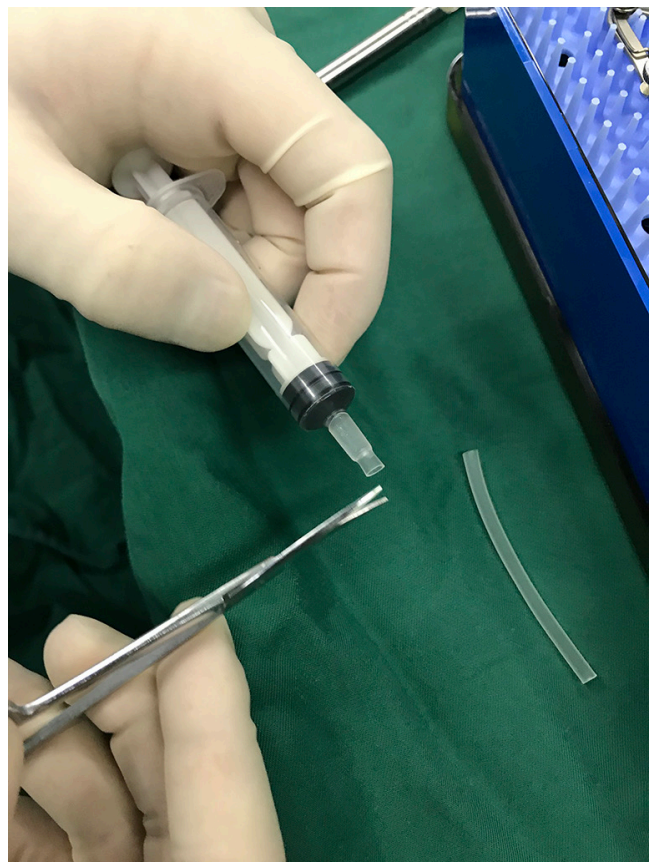

Figure 1 A section of the tube was cut.

by silicone oil remove. An Alcon 23G paracentesis knife was inserted to the vitreous cavity vertical to the sclera in the infratemporal and supratemporal quadrants of the surgical eye, $3.5-4.0 \mathrm{~mm}$ from the cornea. A microcannula was placed at the incision after the paracentesis knife was removed. A perfusion tube was placed at infratemporal area and was connected to a bottle of lactated Ringer's solution. The perfusion pressure of the Constellation vitrectomy machine (Alcon) was set at $30 \mathrm{mmHg}$. (I) Manual oil remove group: a prepared polyethylene tube (which could be cut from the infusion tube) was connected to a $5-\mathrm{mL}$ syringe. A section of the tube was cut with scissors, and approximately

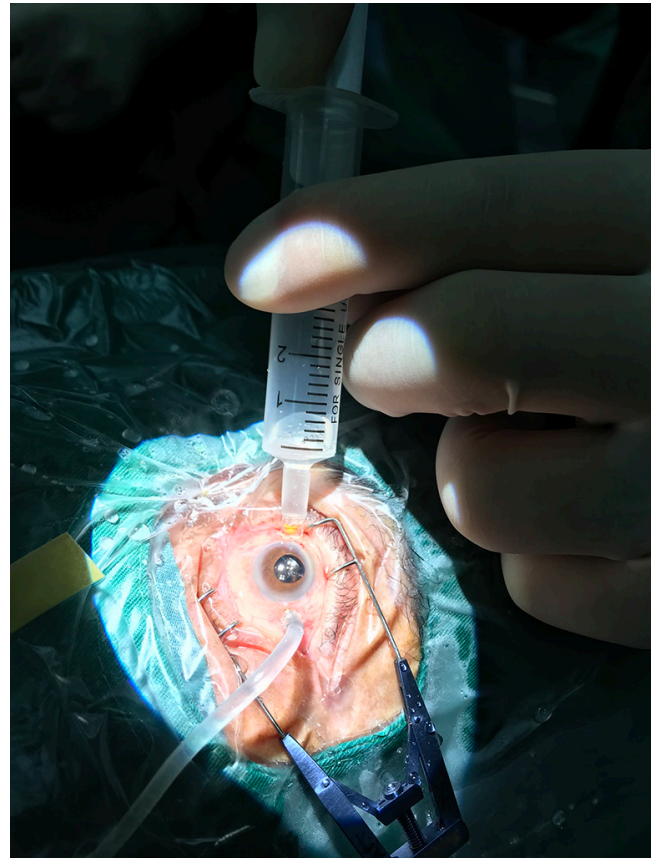

Figure 2 The silicone oil was aspirated into the syringe.

$3 \mathrm{~mm}$ of the tube was exposed (Figure 1). The cut surface of the tube should be smooth and flat to ensure airtightness and avoid unnecessary conjunctival injury. The syringe that was connected to the polyethylene tube was placed perpendicular to the scleral surface onto the ace onto the surface ontoocannula on the supratemporal sclera. The piston handle of the syringe was pulled to generate negative pressure, and the silicone oil was aspirated into the syringe (Figure 2). When aspirating the silicone oil, it is important to release the force according to the load change sensed by the finger to prevent additional pulling if the perfusion fluid is aspirated and the load disappears suddenly. Otherwise, 
Table 2 The average oil remove duration and intraocular pressure at 1 day, 1 week and 1 month after the procedure

\begin{tabular}{lccccc}
\hline Group & $\begin{array}{c}\text { Number } \\
\text { of eyes }\end{array}$ & $\begin{array}{c}\text { Average oil remove } \\
\text { duration }(\mathrm{min})\end{array}$ & $\begin{array}{c}\text { Intraocular pressure at 1 } \\
\text { day after remove }(\mathrm{mmHg})\end{array}$ & $\begin{array}{c}\text { Intraocular pressure at 1 } \\
\text { week after remove }(\mathrm{mmHg})\end{array}$ & $\begin{array}{c}\text { Intraocular pressure at 1 } \\
\text { month after remove }(\mathrm{mmHg})\end{array}$ \\
\hline $\begin{array}{l}\text { Manual oil remove } \\
\text { group }\end{array}$ & 65 & $5.92 \pm 1.34$ & $10.2 \pm 2.7$ & $15.2 \pm 3.5$ & $17.2 \pm 3.1$ \\
$\begin{array}{l}\text { Vitrectomy system } \\
\text { oil remove group }\end{array}$ & 65 & $8.87 \pm 1.68$ & $9.8 \pm 2.4$ & $15.5 \pm 3.1$ & $16.8 \pm 3.4$ \\
$\begin{array}{l}\text { t value } \\
\text { P value }\end{array}$ & - & 11.07 & 0.892 & 0.517 & 0.701 \\
\hline
\end{tabular}

a sudden drop in intraocular pressure may result, leading to eyeball collapse, retinal redetachment, choroidal detachment and even massive suprachoroidal hemorrhage. When the oil and fluid interface was observed in the pupil area, the position of the scleral puncture was adjusted to ensure that the silicone oil was aspirated smoothly and to reduce sudden changes in intraocular pressure caused by the sudden aspiration of the perfusion fluid. The silicone oil was removed completely when the perfusion fluid had a linear shape and no obvious oil droplets floated in the vitreous cavity. (II) The $23 \mathrm{G}$ vitrectomy system oil remove group: Silicone oil was removed by the Constellation $23 \mathrm{G}$ vitrectomy system by the Alcon company (with negative pressure set at $-500 \mathrm{mmHg}, 1 \mathrm{mmHg}=0.133 \mathrm{kPa}$ ), and the remove was stopped when no obvious silicone oil droplets were detected in the vitreous under microscopy. (III) The duration from the beginning to the end of oil remove was recorded for each eye. The scleral and bulbar conjunctival incisions were closed using an 8-0 Ethicon synthetic absorbable surgical suture, and the operation was completed after the eye was sealed with tobramycin and dexamethasone ophthalmic ointment.

\section{Observation indicators}

The following indicators were observed: the oil remove duration of the affected eyes in both groups; the average intraocular pressure of the affected eyes before surgery and at 1 day, 1 week and 1 month after surgery; the total incidence of postoperative complications, including retinal redetachment, silicone oil residue, massive suprachoroidal hemorrhage, choroid detachment, transient intraocular hypotension, vitreous hemorrhage and endophthalmitis.

\section{Statistical analysis}

Data were analyzed with SPSS 13.0 statistical software. Continuous variables were expressed as the mean \pm standard deviation (SD) and compared using an unpaired twosided Student's $t$-test when normal distribution and equal dispersion were confirmed. Categorical variables were expressed as percentages (\%) and compared using $\chi^{2}$ analysis or Fisher's exact test if necessary. Differences with $\mathrm{P}<0.05$ were considered statistically significant.

\section{Results}

The average oil remove durations of the manual group and the vitrectomy system group were $5.92 \pm 1.34$ and $8.87 \pm$ $1.68 \mathrm{~min}$, respectively, and the two groups differed significantly $(\mathrm{P}<0.05$, Table 2$)$.

The average intraocular pressures at 1 day after the procedure for the manual group and the vitrectomy system group were $10.2 \pm 2.7$ and $9.8 \pm 2.4 \mathrm{mmHg}$, respectively. Those at 1 week after the procedure were $15.2 \pm 3.5$ and $15.5 \pm 3.1 \mathrm{mmHg}$, respectively, and those at $1 \mathrm{month}$ after the procedure were $17.2 \pm 3.1$ and $16.8 \pm 3.4 \mathrm{mmHg}$, respectively. The two groups did not differ significantly (Table 2).

In the manual oil remove group, one patient had retinal redetachment, 5 patients had silicone oil residue, no patients had suprachoroidal hemorrhage, 1 patient had choroid detachment, and the incidence rate of complications was $10.7692 \%$. In the vitrectomy system oil remove group, 4 patients had retinal redetachment, 5 patients had silicone oil residue, 1 patient had suprachoroidal hemorrhage, 1 patient had choroid detachment, and the incidence rate 
of complications was $17.69 \%$. The two groups differed significantly in the incidence of complications $\left(\chi^{2}=4.2787\right.$, $\mathrm{P}=0.0386)$. None of the affected eyes were complicated with transient intraocular hypotension (7), vitreous hemorrhage or endophthalmitis.

\section{Discussion}

Silicone oil has been used as an intraocular filler since 1962 (8). Although with the continuous evolution and progress of vitreous surgery, inert gas $(\mathrm{C} 3 \mathrm{~F} 8)$ or filtered air have been used as replacements for silicone oil for intraocular tamponade during vitreous surgery, silicone oil is still irreplaceable in many vitreous surgeries, including those for complicated retinal detachment, proliferative diabetic retinopathy, complicated ocular trauma, intraocular tumors and endophthalmitis. If long-term silicone oil tamponade causes secondary glaucoma, complicated cataract, band-shaped corneal degeneration and silicone oil emulsification $(9,10)$, the silicone oil can be removed normally 3-6 months after vitrectomy, when the retina has recovered, the eye is stable, and there is little emulsified silicone oil.

Consensus indicates that silicone oil remove methods should be efficient, safe, and convenient and that consumables should be low in cost. The manual $23 \mathrm{G}$ silicon oil remove method that we developed has a low cost associated with consumables, is safe, and only requires the connection of a small piece of disposable polyethylene infusion tube to a $5-\mathrm{mL}$ syringe. Oil is removed by the physician pulling the syringe with the fingers. During the procedure, the operator can sense the sudden drop in force when perfusion fluid is aspirated; thus, the pulling on the syringe can be released immediately to prevent eyeball collapse and related complications, such as retinal redetachment, choroid hemorrhage (even massive suprachoroidal hemorrhage), and ciliary body epithelial detachment. The use of $10-\mathrm{mL}$ syringes is not recommended. On one hand, a $10-\mathrm{mL}$ syringe is so long that it is not easy to pull it by hand or to control the direction of the microcannula during the procedure. On the other hand, silicone oil is directly aspirated through the microcannula, and not much pulling force is required to smoothly remove silicone oil with a viscosity of 5000 .

Compared to the conventional 20G method, in which oil is removed by placing a trocar through the scleral plana, the manual $23 \mathrm{G}$ silicone oil remove method is safer: it involves placing the polyethylene tube on the $23 \mathrm{G}$ microcannula at the supratemporal sclera so that the tube is in close contact with the conjunctiva on the scleral surface, which creates negative pressure that is used to remove the silicone oil. In contrast, the $20 \mathrm{G}$ scleral planar oil remove method requires insertion of the cannula into the vitreous cavity; if intraocular perfusion fluid is accidentally removed and the eyeball collapses, it may damage the retina, leading to retinal detachment and bleeding in the eye tissue. Additionally, our manual $23 \mathrm{G}$ method does not require cutting the conjunctiva; in contrast, making a 20G incision leads to considerable damage. Furthermore, our method does not require repeated insertion of the cannula into the eye, which causes retinal rupture close to the incision and leads to recurrent retinal detachment.

In recent years, the vitrectomy system has been used for oil remove. In 2010, Patwardhan et al. (11) reported the application of the vitrectomy system for the remove of silicone oil with a viscosity of 1,000. Song et al. (12) and Garodia et al. (13) used a specialized aspiration system through the $23 \mathrm{G}$ vitrectomy system to remove highly viscous silicone oil and assessed the efficacy and safety this system. With the increasing popularity of minimally invasive $23 \mathrm{G}$ and $25 \mathrm{G}$ vitrectomy systems, these systems have overcome many disadvantages of conventional $20 \mathrm{G}$ oil remove through the scleral plana and have gradually gained favor among many clinicians. However, they still present some difficulties: (I) the scleral puncture diameter is small, making it difficult for the silicone oil to pass through smoothly and making the procedure very time consuming. Additionally, with the high negative pressure, aspiration does not stop immediately when the perfusion fluid in the vitreous cavity is accidentally aspirated; this causes sudden collapse of the eyeball, which may lead to massive suprachoroidal hemorrhage, choroid detachment and recurrent retinal detachment $(14,15)$. (II) Oil remove materials are expensive, increasing the cost of surgery. In addition, this method cannot be performed on a large scale due to lack of appropriate equipment at some medical institutions. Comparing the manual $23 \mathrm{G}$ oil remove method with the $23 \mathrm{G}$ vitrectomy system oil remove method, we made the following observations: (I) the oil remove duration is shorter with the manual method; consequently, this method is more efficient. The reason for this reduced duration is that in the manual method, the polyethylene tube is placed outside of the $23 \mathrm{G}$ cannula of $\mathrm{t}$; this presses the surrounding conjunctiva and sclera perpendicularly and creates excellent sealed negative pressure during remove, so that the silicone oil is aspirated directly from the 
cannula. In contrast, with the vitrectomy system oil remove method, the needle is inserted directly into the cannula for oil remove; the diameter of the needle is too small for the silicone oil to pass through smoothly, making the process very time consuming and less efficient than the manual $23 \mathrm{G}$ oil remove method. (II) The intraocular pressure at 1 day, 1 week and 1 month after the procedure did not differ significantly between the two groups. (III) Due to the large internal diameter of the $23 \mathrm{G}$ cannula, the negative pressure used for oil remove in the manual method was not high, and the operator's fingers could sense the accidental aspiration of the perfusion fluid in the vitreous cavity at all times and stop it immediately. As a result, the incidences of postoperative retinal redetachment, silicone oil residue, massive suprachoroidal hemorrhage and choroidal detachment were lower than those of the vitrectomy system oil remove method, making the manual method safer.

\section{Conclusions}

The objectives of the oil remove procedure are to remove as much silicone oil as possible, reduce the operation duration and improve surgical efficiency under the premise of preventing complications (16-20). An analysis of the effects of manual $23 \mathrm{G}$ oil remove shows that the procedure is highly efficient and safe. Therefore, we offer an efficient, safe, simple and economical silicon oil remove method that is convenient for extensive use by medical institutions at all levels.

\section{Acknowledgments}

First and foremost, I would like to show my deepest gratitude to my supervisor, Dr. Yong Liang, a respectable, responsible and resourceful scholar who has provided me with valuable guidance in every stage of the writing of this thesis. Without his enlightening instruction, impressive kindness and patience, I could not have completed my thesis. His keen and vigorous academic observation has enlightened me not only regarding this thesis but also regarding my future study. I extend my thanks to Mrs. JL and Mr. QL for their kindness and help. I would also like to thank all my teachers, who have helped me to develop the fundamental and essential academic competence. My sincere appreciation also goes to the teachers from the Guangxi Medical University, who participated this study with great cooperation. Last but not least, I would like to thank all my friends, especially my college classmate Mr.
Haorang Lu for his encouragement and support.

Funding: Self-financing Scientific Research Project of the Health and Family Planning Commission of Guangxi Zhuang Autonomous Region (No. Z20180388). Scientific Research Foundation Project of Guangxi Health Commission (No. Z20180388).

\section{Footnote}

Reporting Checklist: The authors have completed the STROBE reporting checklist. Available at http://dx.doi. org/10.21037/apm-20-949

Data Sharing Statement: Available at http://dx.doi. org/10.21037/apm-20-949

Conflicts of Interest: All authors have completed the ICMJE uniform disclosure form (available at http://dx.doi. org/10.21037/apm-20-949). The authors have no conflicts of interest to declare.

Ethical Statement: The authors are accountable for all aspects of the work in ensuring that questions related to the accuracy or integrity of any part of the work are appropriately investigated and resolved. The study was approved by the ethics committee of the hospital, and all patients signed informed consent.

Open Access Statement: This is an Open Access article distributed in accordance with the Creative Commons Attribution-NonCommercial-NoDerivs 4.0 International License (CC BY-NC-ND 4.0), which permits the noncommercial replication and distribution of the article with the strict proviso that no changes or edits are made and the original work is properly cited (including links to both the formal publication through the relevant DOI and the license). See: https://creativecommons.org/licenses/by-nc-nd/4.0/.

\section{References}

1. Meng X, Zhou M, Liu H. Treatment of tractional retinal detachment by vitrectomy combined with silicone oil tamponade. Chinese Journal of Gerontology 2015;(2):385-7.

2. Siyal NA, Hargun LD, Wahab S. Passive removal of silicone oil through 23 gauge transconjunctival sutureless vitrectomy system. Pak J Med Sci 2016;32:652-6.

3. Cheng H, Zhang SG, Wang J, et al. Tolerance of rabbit 
retina to silicon oil RMN3. Chinese Journal of Ocular Fundus Diseases 2009;25:63-5.

4. Yang H, Wang F, Yi J, et al. Study of modified two incisions silicone oil removal with a $23 \mathrm{G}$ transconjunctival sutureless vitrectomy system. International Journal of Ophthalmology 2015;15:72-3.

5. Wan X, Liang Y. Effects of heavy silicone oil tamponade in the treatment of retinal detachment due to macular hole in highly myopic eyes in elderly patients. Chinese Gerontology 2012;32:2697-9.

6. Tan HS, Dell'omo R, Mura M. Silicone oil removal after rhegmatogenous retinal detachment: comparing techniques. Eye (Lond) 2012;26:444-7.

7. Brănişteanu DC, Moraru A, Bîlha A. Anatomical results and complications after silicone oil removal. Rom J Ophthalmol 2017;61:261-6.

8. Scheerlinck LM, Schellekens PA, Liem AT, et al. Retinal sensitivity following intraocular silicone oil and gas tamponade for rhegmatogenous retinal detachment. Acta Ophthalmol 2018;96:641-7.

9. Lin Z, Ke ZS, Zheng Q, et al. Passive Removal of Silicone Oil with Temporal Head Position through Two 23-Gauge Cannulas. J Ophthalmol 2016;2016:4182693.

10. Tyagi M, Basu S. Glue-assisted retinopexy for rhegmatogenous retinal detachments (GuARD): A novel surgical technique for closing retinal breaks. Indian J Ophthalmol 2019;67:677-80.

11. Patwardhan SD, Azad R, Shah V, et al. The safety and efficacy of passive removal of silicone oil with 23 -gauge transconjunctival sutureless system. Retina 2010;30:1237-41.

12. Song ZM, Chen D, Ke ZS, et al. A new approach for

Cite this article as: Wan X, Li J, Liu Q. Effectiveness of different silicone oil remove methods after vitrectomy and light silicone oil tamponade in elderly patients. Ann Palliat Med 2020;9(3):1013-1019. doi: 10.21037/apm-20-949 active removal of 5,000 centistokes silicone oil through 23-gauge cannula. Retina 2010;30:1302-7.

13. Garodia VK, Kulkarni A. Silicone oil removal using vitrectomy machine: a simple and safe technique. Retina 2001;21:685-7.

14. Suzuki R, Susanna R Jr. Early transconjunctival needling revision with 5-fluorouracil versus medical treatment in encapsulated blebs: a 12-month prospective study. Clinics 2013;68:1376-9.

15. Bahrani HM, Fazelat AA, Thomas M, et al. Endophthalmitis in the era of small gauge transconjunctival sutureless vitrectomy-meta analysis and review of literature. Semin Ophthalmol 2010;25:275-82.

16. Xu Y, Wang C. Analysis of Vitrectomy in Treatment of 28 Eyes with Intraocular Foreign Body. Medical \& Pharmaceutical Journal of Chinese People's Liberation Amy 2013;25:37-9.

17. Chaudhry IA, Shamsi FA, Al-Harthi E, et al. Incidence and visual outcome of endophthalmitis associated with intraocular foreign bodies. Graefes Arch Clin Exp Ophthalmol 2008,246:181-6.

18. Chow DR, Garretson BR, Kuczynski B, et al. External versus internal approach to the removal of metallic intraocular foreign bodies. Retina 2000;20:364-9.

19. Amato JE, Akduman L. Incidence of complications in 25 -gauge transconjunctival sutureless vitrectomy based on the surgical indications. Ophthalmic Surg Lasers Imaging 2007;38:100-2.

20. Grzybowski A, Pieczynski J, Ascaso FJ. Neuronal complications of intravitreal silicone oil: an updated review. Acta Ophthalmol 2014;92:201-4. 